\title{
Clinicopathological spectrum of Keratinocytic tumors of skin in a tertiary care centre
}

\author{
Sujatha $\mathbf{R}^{1}$, Tricha Kulhallii,*, Manjunatha $\mathbf{Y . A}^{3}$ \\ ${ }^{1}$ Associate Professor, ${ }^{2}$ Post Graduate, ${ }^{3}$ Professor and HOD, Dept. of Pathology, Dr. B.R. Ambedkar Medical College, Bangalore, \\ Karnataka, India
}

*Corresponding Author: Tricha Kulhalli

Email: drsujatha02@gmail.com

Received: $21^{\text {st }}$ February, 2018

Accepted: $14^{\text {th }}$ May, 2018

\begin{abstract}
Introduction: Skin is the largest organ in the body and tumors can arise from any part of the skin. Skin cancer represents the most common form of malignant disease in the world. ${ }^{1}$ In India, malignant skin tumors constitute about $1-2 \%$ of all cancers. National Cancer Registry Programme, Indian council of medical research- Consolidated report of the Population based cancer registries reported cumulative incidence of skin cancer varying from 0.5 to 2 per 100000 population. ${ }^{2}$ Non melanoma skin cancers are associated with substantial morbidity, including loss of function and disfigurement and their treatment is costly. Early diagnosis can reduce morbidity and cost. There is a definite role of pathologists in the management of tumors.

Aim: To study the different Clinicopathological features of Keratinocytic skin tumors and analyze the tumors according to age, sex, site and incidence.

Materials and Methods: This is a prospective study from June 2015 to August 2017 for a period of 26 months. Excision biopsy specimens and skin punch biopsies sent for histopathological evaluation to the Department of Pathology, Dr. B. R. Ambedkar Medical College, were studied.

Results: Out of the 140 skin tumors studied, 130 were benign and 10 were malignant. Incidence of benign tumors was most common in the younger age groups. Premalignant tumors were more common in the $4^{\text {th }}$ decade. These tumors showed an overall male preponderance. However, malignant tumors were found to be more common in females and in the older age groups. The sun exposed areas were the most common site of both benign and malignant Keratinocytic tumors. Squamous cell carcinoma was found to be more common than Basal cell carcinoma.

Conclusion: We studied, 140 cases of Keratinocytic tumors of skin. 87.2\% were benign, 5.7\% were Pre-Malignant and $7.1 \%$ were malignant. Most common benign tumor in our institution was verruca vulgaris and the most common malignant tumor in our institution was squamous cell carcinoma. Although malignant tumors were seen in older age group, benign tumors showed prevalence in younger patients. Our findings mostly correlate with the published Indian literature.
\end{abstract}

Keywords: Non melanocytic skin tumors, Keratinocytic tumors, Keratoacanthoma, Bowen's disease, Pre-malignant skin tumors.

\section{Introduction}

Skin is the largest organ in the body and tumors can arise from any part of the skin. Skin cancer represents the most common form of malignant disease in the world. ${ }^{1}$ The ability to properly diagnose and treat tumors is a vital skill for all clinicians.

In India, Malignant skin tumors constitute about 1$2 \%$ of all cancers. ${ }^{2}$ Despite growing public awareness of harmful effects of sun exposure, incidence continues to rise. Non melanoma skin cancers are associated with substantial morbidity, including loss of function and disfigurement and their treatment is costly.

Early diagnosis can reduce morbidity and cost. There is a definite role of pathologists in the management of tumors. But due to diversity of these tumors, there can be confusion regarding nomenclature of these tumors. ${ }^{3}$ As a result, the study of skin tumor is perhaps more interesting and challenging than any other tumors.

Differences in trends and rates of skin cancer may be due to variation in skin types, geographical latitudes, occupational exposure, behavior in terms of sun exposure and skin protection and differences in disease awareness and surveillance. ${ }^{4}$
Hence, the aim was to study the different histopathological features of Keratinocytic skin tumors and to study the variations of skin tumors and analyze the tumors according to age, sex, site and incidence.

\section{Materials and Methods}

This study was undertaken in the department of Pathology at the Histopathology division of Dr. B.R. Ambedkar Medical College and Hospital, Bangalore, from June 2015 to August 2017. All specimens were fixed in $10 \%$ formalin, processed and embedded in paraffin. Three to five microns thick sections were taken and then stained with Haematoxylin and Eosin stains and evaluated under light microscopy. All Keratinocytic tumors of the Skin classified as per the WHO classification were included in the study. Hematolymphoid tumors, soft tissue tumors, neural tumors, metastatic tumors of skin, inherited tumor syndromes, adnexal and melanocytic tumors were excluded from the study. Relevant clinical data was retrieved and gross findings were noted. A total of 140 Keratinocytic tumors were diagnosed during a period of 26 months. 


\section{Results}

140 Keratinocytic tumors of the skin were analyzed. These tumors were found to have a slight Male preponderance [Table 1]. Of all the tumors studied 122 were benign, 8 were Premalignant and 10 were malignant cases [Table 2]. In our study, Keratinocytic tumors were found to be common in all age groups. Incidence of Benign tumors was more common in the younger age groups, Pre-malignant was more common in the $4^{\text {th }}$ decade whereas the malignant tumors were more common in the older age groups. Among the 122 benign Keratinocytic tumors, 107 were verruca vulgaris and the peak age incidence was found in the $2^{\text {nd }}$ to $3^{\text {rd }}$ decade [Table 3] and male to female ratio was 1.22: 1 [Table 4]. Squamous cell carcinomas were more common than the Basal cell carcinomas and were also found to be more common in the females [Table 5]. Majority of the benign tumors were that of Verruca vulgaris for which extremities was the most common site [Table 6]. Sun exposed areas like the head and neck, thorax, back and abdomen and extremities was the most common site for both Premalignant and Malignant lesions.

\section{Discussion}

Keratinocytic tumors comprise a large spectrum of lesions ranging from benign proliferations to malignant squamous cell carcinomas which show aggressive growth and have a metastatic potential. Keratinocytic tumors are very frequent. Despite their low mortality rate, they pose a significant public health problem, the main etiologic factor is UV radiation which causes, DNA alterations, which during DNA replication may lead to CC: TT mutations in the TP53 tumor suppressor gene. ${ }^{1}$

Three most frequent primary skin cancers are Basal Cell Carcinoma (BCC), Squamous Cell Carcinoma (SCC) and malignant melanoma. Together SCC and BCC are referred to as Non-Melanoma Skin Cancers (NMSC).

The current study was done for a period of 26 months and shows the histopathological findings of 140 Keratinocytic tumors diagnosed in the Pathology Department of Dr. B. R. Ambedkar Medical College, Bangalore.

Keratinocytic tumors were found to have a slight Male preponderance. $74(52.8 \%)$ were males and 66 $(47.2 \%)$ were females. [Table 1]. 122 were benign, 8 were Premalignant and 10 were malignant cases [Table 2]. As per National Cancer Registry Programme, Indian council of medical research. Consolidated report of the Population based cancer registries incidence of skin malignancies is $0.5-2 \%$ and our study showed incidence of $7.1 \%$ (10 out of 140 ) this variation is probably due to the duration of our study, the representative population in the different studies available and the limited sample size. Keratinocytic tumors were found to be prevalent in all age groups. [Table 3]. Study by Nandyal et al ${ }^{5}$ also showed similar age range benign in the $3^{\text {rd }}$ to $5^{\text {th }}$ decade and malignant in the $5^{\text {th }}$ to $7^{\text {th }}$ decade with a male preponderance of $71.91 \%$.

Table 1: Age \& gender specific distribution in keratinocytic tumors

\begin{tabular}{|l|c|c|c|}
\hline \multicolumn{1}{|c|}{ Age(years) } & Males & Females & Total \\
\hline$<10$ & 5 & 3 & 8 \\
\hline $11-20$ & 13 & 15 & 28 \\
\hline $21-30$ & 12 & 13 & 25 \\
\hline $31-40$ & 13 & 9 & 22 \\
\hline $41-50$ & 12 & 10 & 22 \\
\hline $51-60$ & 9 & 7 & 16 \\
\hline $61-70$ & 3 & 3 & 6 \\
\hline$>70$ & 7 & 6 & 13 \\
\hline Total & $74(52.8 \%)$ & $66(47.1 \%)$ & 140 \\
\hline
\end{tabular}

Table 2: Distribution of the different types of tumors

\begin{tabular}{|l|c|}
\hline & Total \\
\hline Benign & \\
\hline Verruca vulgaris & 107 \\
\hline Squamous papilloma & 7 \\
\hline Seborrhoeic keratosis & 8 \\
\hline Premalignant & \\
\hline Bowen's Disease & 2 \\
\hline Actinic Keratosis & 4 \\
\hline Keratoacanthoma & 2 \\
\hline Malignant & \\
\hline Basal cell Carcinoma & 3 \\
\hline Squamous cell carcinoma & 7 \\
\hline Total & 140 \\
\hline
\end{tabular}


Table 3: Age wise distribution of different tumors of skin

\begin{tabular}{|c|c|c|c|c|c|c|c|c|c|}
\hline \multirow{2}{*}{$\begin{array}{c}\text { Histopathological } \\
\text { tumor types }\end{array}$} & \multicolumn{9}{|c|}{ Age group (years) } \\
\hline & $<\mathbf{1 0}$ & 11-20 & $21-30$ & $31-40$ & $41-50$ & $51-60$ & $61-70$ & $>70$ & Tota \\
\hline \multicolumn{10}{|l|}{ Benign } \\
\hline Verruca vulgaris & 8 & 27 & 21 & 17 & 13 & 11 & 3 & 7 & 107 \\
\hline Squamous papilloma & - & - & 3 & 2 & - & 1 & 1 & - & 7 \\
\hline Seborrhoeic keratosis & - & 1 & 1 & - & 1 & - & 2 & 3 & 8 \\
\hline \multicolumn{10}{|l|}{ Premalignant } \\
\hline Bowen's Disease & - & - & - & - & 1 & 1 & - & - & 2 \\
\hline Actinic Keratosis & - & - & - & - & 4 & - & - & - & 4 \\
\hline Keratoacanthoma & - & - & - & 1 & 1 & - & - & - & 2 \\
\hline \multicolumn{10}{|l|}{ Malignant } \\
\hline Basal cell Carcinoma & - & - & - & - & - & 1 & - & 2 & 3 \\
\hline $\begin{array}{l}\text { Squamous cell } \\
\text { carcinoma }\end{array}$ & & & & 2 & 2 & 2 & - & 1 & 7 \\
\hline Total & 8 & 28 & 25 & 22 & 22 & 16 & 6 & 13 & 140 \\
\hline
\end{tabular}

In the present study the most common benign Keratinocytic tumor was Verruca Vulgaris $(81.5 \%)$ which correlates with the studies conducted by Muhammad Usman Shams et al $(78 \%)^{6}$ and Bari V et al $(72 \%) .{ }^{7}$ Here, the skin exhibits hyperkaratosis, koilocytic change of keratinocytes along with prominent keratohyaline granules.

The most common site of involvement of verruca was the extremities (43.9\%) [Table 6] which correlates with the study done by Young $\mathrm{R}$ et $\mathrm{al}^{8}$ who also showed extremities to be the most common site (61.9\%) comparing verruca vulagris with other keratinocytic lesions, no comparative reference could be found. In our study, verrucas were the commonest nonmalignant keratinocytic lesion comprising and this may be due to the fact that viral warts are quite frequent in children and adolescents. ${ }^{3}$

Squamous papilloma [Fig. 1] showed increased incidence in 2nd and 3rd decade with female preponderance. [Table $3 \& 4$ ] The tissue shows a polypoidal structure exhibiting acanthosis, hypergranulosis, hyperkeratosis, papillomatosus, along with dense fibrovascular core.

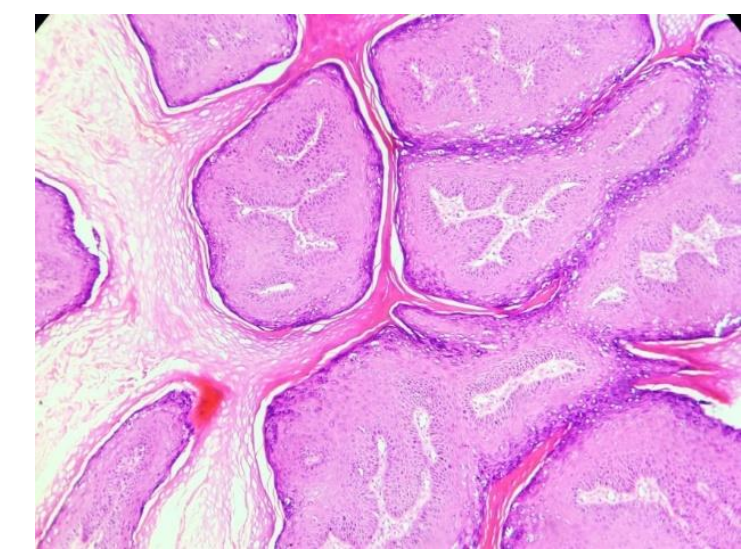

Fig. 1: Microphotograph of Squamous papilloma showing a papillary lesion with arborizing fibrovascular cores lined by keratinizing mature squamous epithelium ( $\mathrm{H} \& \mathrm{E}$ at $40 \mathrm{x})$

Table 4: Sex wise distribution of benign tumors of skin

\begin{tabular}{|l|c|c|c|}
\hline Histological tumor type & Incidence & Male & Female \\
\hline Bowen's Disease & $2(1.5 \%)$ & 0 & 2 \\
\hline Actinic Keratosis & $4(3.07 \%)$ & 3 & 1 \\
\hline Verruca vulgaris & $107(81.5 \%)$ & 59 & 48 \\
\hline Seborrhoeic keratosis & $8(6.15 \%)$ & 5 & 3 \\
\hline Keratoacanthoma & $2(1.5 \%)$ & 1 & 1 \\
\hline Squamous papilloma & $7(5.3 \%)$ & 2 & 4 \\
\hline Total & 130 & 70 & 60 \\
\hline
\end{tabular}

Seborrhoeic keratosis was diagnosed in $8(6.15 \%)$ cases in our study and was the second most common benign tumor with slight female preponderance [Table 3 \& 4]. The skin tissue exhibits small cuboidal keratinocytes without cytologic atypia. Usually has "horn pseudocysts" these are round intralesional cysts of loose keratin and the lesion extends to a uniform depth and one could draw a horizontal line parallel to the epidermal surface underlying the lesion.

Rajesh $\mathrm{G}$ et al. ${ }^{9}$ observed a male to female ratio of 1:1.04 and the most common age group affected was 60 years. The most common variant of Seborrhoeic 
keratosis is the acanthotic type ${ }^{1}$. In our study too, acanthotic type [Fig. 2] was the most commonly observed variant.

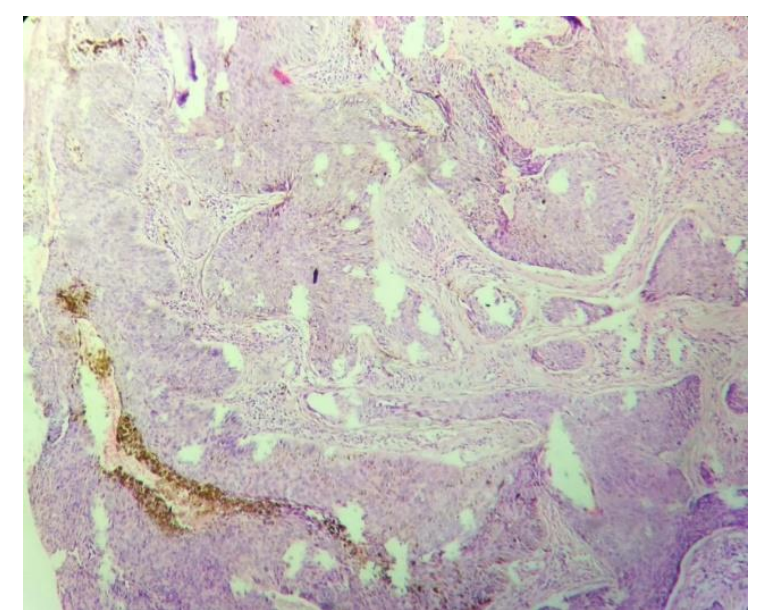

Fig. 2: Microphotograph of seborrheic keratosisacanthotic type showing thick layer of basal cells mixed with pseudohorn cysts ( $\mathrm{H} \& \mathrm{E}$ at 10x)

The occurrence of NMSCs is closely linked to ultraviolet irradiation, as they are diagnosed on chronically sun-exposed skin, occur among older individuals, and in lighter skin. ${ }^{10}$ Actinic keratosis are believed to be precursor lesions to invasive squamous cell carcinoma. Few also believe it to be a low-grade SCC in situ. ${ }^{11}$ They are induced by ultraviolet radiation and can develop into squamous cell carcinoma, and they are the most common pre-malignant lesions in humans the other being Bowen's disease. ${ }^{12}$ In one of the patients, coexistence of Bowenoid actinic keratosis and minimally invasive Squamous cell carcinoma was reported by us [Fig. 3]. This finding directly implies the premalignant nature of this condition.

Skin in actinic keratosis shows, Basal cell and squamous layer atypia and disorderly maturation, with hyperkeratosis and parakeratosis with absence of granular layer and dermis showing elastosis and dense chronic inflammatory cell infiltrate.

In our study, 4 cases of actinic keratosis were reported, all of which were in the fourth decade and were more common in males $(75 \%)$ with sun exposed areas as the most commonly involved site [Table 6]. These findings correlate with the study done by Kennedy C. et al who concluded the same. ${ }^{13}$

We also reported 2 cases of Bowen's disease both in females between the $4^{\text {th }}$ to $6^{\text {th }}$ decades, one in the vulval area (also called currently as vulval intraepithelial neoplasia) [Fig. 4] and the other in the breast region [Fig. 5].

Table 5: Sex wise distribution of malignant tumors of skin

\begin{tabular}{|l|c|c|c|}
\hline \multicolumn{1}{|c|}{ Histopathological tumor types } & Incidence & Male & Female \\
\hline Basal cell carcinoma & $3(30 \%)$ & 2 & 1 \\
\hline Squamous cell carcinoma & $5+2(70 \%)$ & 2 & 5 \\
\hline Total & 10 & 4 & 6 \\
\hline
\end{tabular}

Table 6: Site wise distribution of the Keratinocytic tumors

\begin{tabular}{|c|c|c|c|c|c|}
\hline \multirow{2}{*}{$\begin{array}{l}\text { Histopathological } \\
\text { tumor types }\end{array}$} & \multicolumn{4}{|c|}{ Site } & \multirow[b]{2}{*}{ Total } \\
\hline & Head and neck & $\begin{array}{l}\text { Thorax, } \\
\text { Back and } \\
\text { Abdomen }\end{array}$ & $\begin{array}{c}\text { Genital } \\
\text { area }\end{array}$ & Extremities & \\
\hline \multicolumn{6}{|l|}{ Benign } \\
\hline Verruca vulgaris & 18 & 26 & 16 & 47 & 107 \\
\hline Squamous papilloma & 2 & 2 & - & 3 & 7 \\
\hline Seborrhoeic keratosis & 1 & 5 & - & 2 & 8 \\
\hline \multicolumn{6}{|l|}{ Pre-Malignant } \\
\hline Bowen's Disease & - & 1 & 1 & - & 2 \\
\hline Actinic Keratosis & 1 & 1 & - & 2 & 4 \\
\hline Keratoacanthoma & - & 2 & - & - & 2 \\
\hline \multicolumn{6}{|l|}{ Malignant } \\
\hline Basal cell Carcinoma & 2 & 1 & - & - & 3 \\
\hline $\begin{array}{l}\text { Squamous cell } \\
\text { carcinoma }\end{array}$ & 1 & 1 & 2 & 3 & 7 \\
\hline Total & 25 & 39 & 19 & 57 & 140 \\
\hline
\end{tabular}



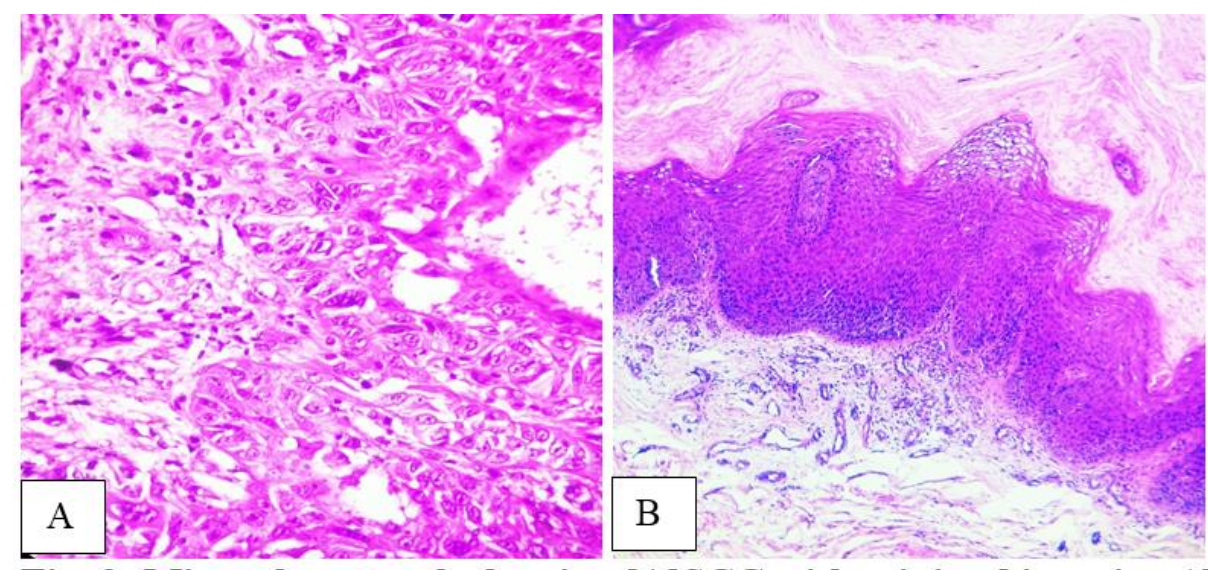

Fig. 3: Microphotograph showing; A: SCC with minimal invasion $(\mathrm{H} \& \mathrm{E}$ at 40x); B: The same patient showing Bowenoid actinic keratosis in another lesion. ( $\mathrm{H} \& \mathrm{E}$ at $10 \mathrm{x}$ )
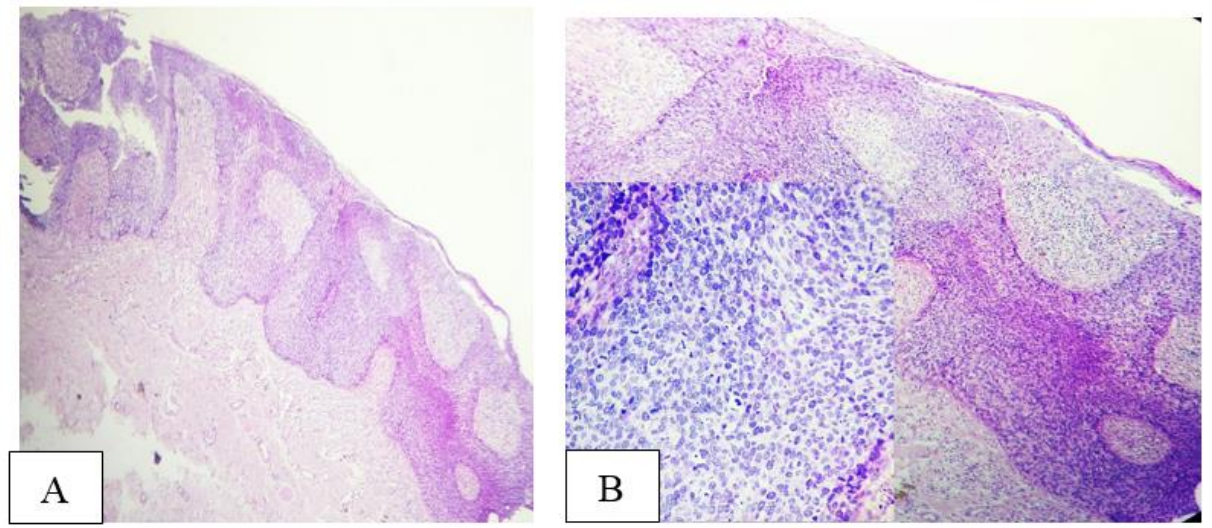

Fig. 4: Microphotograph of Vulval Intraepithelial neoplasia III showing; A: Hyperkeratosis and parakeratosis, Acanthosis with club shaped rete ridges; B: Disorientation of the cells above the basal cell layer with variable extension to the surface, Intact basement membrane inset shows numerous mitotic figures.(H \& E 40 X)

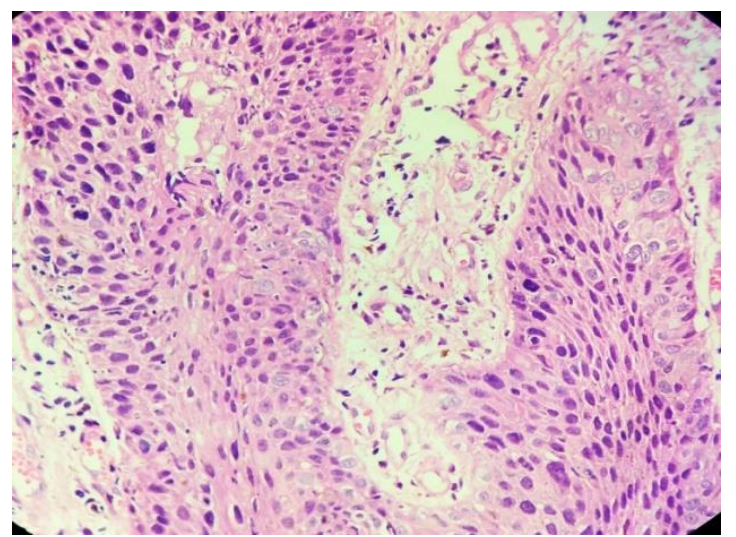

Fig. 5: Microphotograph of Bowen's disease showing atypical squamous cells proliferating through the whole thickness of the epidermis. The entire lesion is confined to the epidermis and does not invade into the dermis. The cells in Bowen's disease are highly atypical. (H \& E, 10X)
We reported two cases of Keratoacanthoma: both in the middle aged group and both were on the back with equal gender distribution [Fig. 5]. One of which also showed features of micro invasion. The tissue showed, a central crater filled with keratin without a granular layer it also exhibited irregular infiltrating squamous nests and islands, accompanied by marked inflammatory infiltrate. 

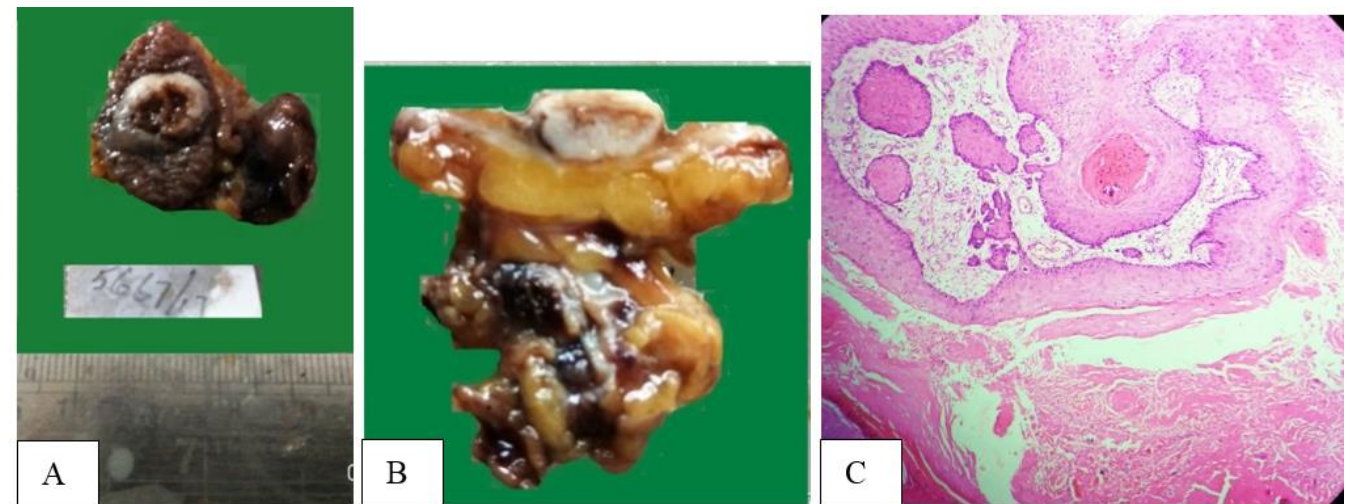

Fig. 6: A: Gross image of Keratoacanthoma; B: Cut surface of the same specimen showing a well formed crater; $\mathrm{C}$ Microphotograph showing central crater filled with keratin but no granular layer, irregular infiltrating squamous nests and islands, accompanied by marked inflammatory infiltrate. (H \& E, 10X)

Basal Cell Carcinoma (BCC) shows a marked regional variation in incidence. Decreased incidence has been reported in northern Europe as opposed to extremely high incidence in Australia. BCC is very rare with dark skin colored individuals and has a slight male preponderance and found majorly on the head and neck regions. ${ }^{1,3}$ Although $\mathrm{BCC}$ is the commonest form of skin cancer worldwide, various studies from India have reported SCC as the most prevalent skin malignancy.,
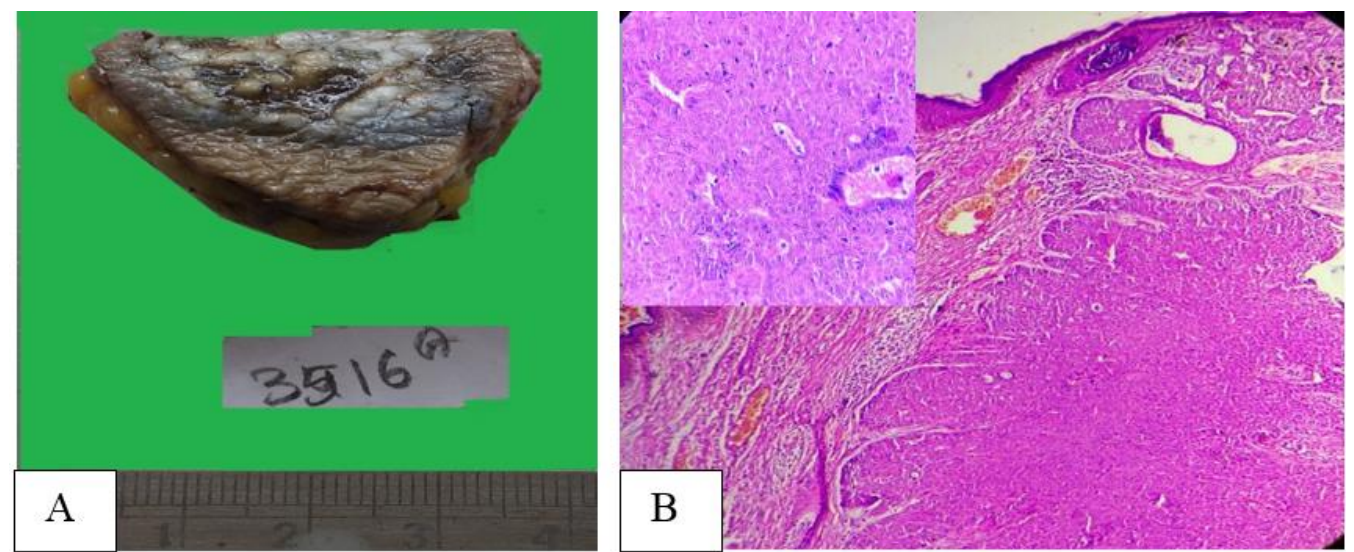

Fig. 7: A: Gross image of nodular BCC showing superficial ulceration with raised margins; B: Microphotograph of Basal Cell carcinoma showingnodular arrangement of atypical basaloid cells with peripheral palisading. Inset higher magnification of the same. ( $\mathrm{H} \& \mathrm{E}, 40 \mathrm{X})$

The discrepancies in the presentations of skin cancers can be related to differences in exposure to sun either occupational or due to geographical latitudes or the various skin types. Unawareness and poor surveillance could also play a major role. ${ }^{1,9}$

The most common variant of BCC in our study was the nodular type [Fig. 7], which shows large tumor nodules in the dermis that are generally circumscribed.

Similar to various studies from India, the current study shows the most common histologic type of skin cancers is SCC (70\%) which is similar to the observations made by Chakravarthy RC et al, ${ }^{14}$ Deo SV et al, ${ }^{15}$ Budharaja SN et al ${ }^{16}$ and Bari $\mathrm{V}$ et al. ${ }^{7}$

We also recorded 2 cases of the verrucous variant of SCC, both in females, one of which was around the waist and another one the leg. Verrucous carcinoma is a less common variant of invasive squamous-cell carcinoma. These were single, cauliflower-shaped tumors, like large warts. Microscopically it showed, epidermis with hyperkeratosis, papillomatosis, hypergranulosis, acanthosis, rete ridges were bulbous with "bulldozing" pattern and invaded deep dermis in a pushing manner.

The maximum number of malignant tumors were found in $4^{\text {th }}$ to $7^{\text {th }}$ decade which was similar to study by Bari $\mathrm{V}$ et al who also showed maximum malignant tumors in the $7^{\text {th }}$ decade. ${ }^{\text {? }}$

\section{Conclusion}

We studied 140 cases of Keratinocytic tumors of skin. $87.2 \%$ were benign, $5.7 \%$ were Pre-Malignant and $7.1 \%$ were malignant. The most common benign tumor was verruca vulgaris and the most common malignant tumor was squamous cell carcinoma. 
Although malignant tumors were seen in older age group, benign tumors showed prevalence in younger patients. Our finding mostly correlate with the published Indian literature.

Concluding our study in which age, sex, distribution and the morphologies of various Keratinocytic tumors were studied. Routine surveillance of skin is recommended to identify premalignant and precursor lesions of skin cancer to avoid them from turning into aggressive malignancies. This is especially so for certain syndromic disorders that have a tendancy towards skin cancer for example xeroderma pigmentosum which has predilection towards squamous cell carcinoma.

Creating awareness about the effects of prolonged exposure to sun and the use of protective along with UV creams will prove to have important health implications since the incidence of skin tumors continues to rise.

Hence, early diagnosis can reduce morbidity, cost and overall prognostic outlook. Pathologists hence play a major role in the management of Keratinocytic tumors.

\section{References}

1. Elder D Lever W. Lever's Histopathology of skin. $9^{\text {th }}$ ed. Philadelphia: Wolters Kluwer Health/Lippincott Williams \& Wilkins; 2005;705-928.

2. National Cancer Registry Programme, Indian council of medical research. Consolidated report of the Population based cancer registries. 1990-96;35-113.

3. Bari V, Murarkar P, Gosavi A, Sulhyan K. Skin TumorsHistopathological Review of 125 Cases. Indian Medical Gazette. 2014;418-427.

4. Le Boit PE. WHO classification of tumors of skin. $3^{\text {rd }}$ ed. Lyon: IARC Press; 2006.

5. Koh D, Wang H, Lee J, Chia K S, Lee H P and Goh C L, "Basal cell carcinoma, squamous cell carcinoma and melanoma of Skin; analysis of Singapore Cancer Registry data 1968-97", British Journal of Dermatalogy, 2003:148;(6)1161-1166.

6. Nandyal SS, Puranik BR. Study of demographic profile of skin tumors in a tertiary care hospital. IJCRR. 2014;6(16):24-28.

7. Muhammad Usman Shams, Usman Hassan, Farid Ahmed Khan and Sabrina Suhail Pal- Demographic Profile of Keratinocyte Tumours. Journal of Islamabad Medical \& Dental College (JIMDC). 2012(2):72-76.
8. Ahmed Zahr Allayali, Khulood Fallatah, Sarah Alorfi and Bayan Mogharbel- Prevalence and Risk Factors of Verruca Vulgaris among Primary School Children in Madinah and Jeddah, Saudi Arabia Allayali et al., J Clin Exp Dermatol Res. 2016;8:1.

9. Young R., Jolley D., Marks R.-Comparison of the use of standardized diagnostic criteria and intuitive clinical diagnosis in the diagnosis of common viral warts (verruca vulgaris), Arch dermatol. 1998;134;1586-89.

10. Rajesh G, Thappa DM, Jaisankar TJ, Chandrashekar L. Spectrum of seborrheic keratoses in south Indians: A clinical and dermoscopic study. Indian J Dermatol Venereol Leprol. 2011;77:483-8.

11. Thompson SC, Jolley D, Marks R N. Reduction of solar keratoses by regular sunscreen use. Engl J Med. 1993;329(16): 1147-51.

12. Ackerman $\mathrm{AB}$, Mones JM. Solar (actinic) keratosis is squamous cell carcinoma. Br J Dermatol. 2006;155(1):922.

13. Goldberg LH, Mamelak AJ. Review of actinic keratosis. Part I: etiology, epidemiology and clinical presentation. $J$ Drugs Dermatol. 2010;9:1125-32.

14. Kennedy C, Bajdik CD, Willemze R, De Gruijl FR, Bouwes Bavinck JN; Leiden Skin Cancer Study. The influence of painful sunburns and lifetime sun exposure on the risk of actinic keratoses, seborrheic warts, melanocytic nevi, atypical nevi, and skin cancer. J Invest Dermatol. 2003;120:1087-93.

15. Charkravorthy RC and Choudhuri DR. Malignant neoplasms of the skin in Eastern India. The Indian Journal of Cancer. 1968:5:133-144.

16. Deo SV. Surgical management of skin cancers: Experience from a regional cancer centre in North India. Indian Journal of Cancer. 2005;42:145-50.

17. Budharaja SN, Pillai VCV, Periyanagam WJ, Kaushik SP and Bedi BMS. Malignant neoplasms of skin in Pondicherry- a study of 102 cases. The Indian Journal of Cancer, 1972:284-295.

How to cite this article: Sujatha R, Kulhalli T, Manjunatha Y.A. Clinicopathological spectrum of Keratinocytic tumors of skin in a tertiary care centre. Indian J Pathol Oncol. 2018;5(4):524-530. 